\title{
Comparing Fisch's artery-sparing technique with the microsurgical subinguinal varicocelectomy
}

Original
Article

\author{
Amr Alahwany
}

Department of Andrology, Cairo University, Cairo, Egypt

\begin{abstract}
Objective: The aim was to evaluate the reduction of operation time using a new artery-sparing varicocelectomy technique. Patients and methods: This study compares a new surgical technique introduced by Fisch and colleagues, which elevates the testicular artery and ligates the pampiniform plexus in one or more vein groups, with subinguinal microsurgical varicocelectomy. The study was conducted retrospectively on a control group of 51 patients who had conventional microsurgical varicocelectomy (group 1) and the experimental group of 44 patients who underwent the new technique (group 2).

Results: We compared the outcome measures including operative time (in minutes), postoperative complications, semen percentage improvement, and pregnancy outcome rate. Both groups had significantly improved semen count, motility, and abnormal form improvements. Group 2 had significantly greater sperm motility and $11.6 \%$ less abnormal forms. Both groups had similar pregnancy rates ( $40 \%$ for the microsurgical group vs. $35.7 \%$ for the Fisch technique group; $\mathrm{P}=0.3$ ). Group 1 had an average operating time of $94 \pm 6.9$ min compared with $44.5 \pm 8.4$ min for group $2(\mathrm{P}=0.001)$.

Conclusion: The Fisch technique dramatically reduces operative time with similar patient outcomes when compared with the traditional subinguinal microsurgical varicocelectomy.
\end{abstract}

Key Words: Artery and lymphatic sparing, infertility, operative time, varicocelectomy

Received: 11 June 2018, Accepted: 19 November 2018

Corresponding Author: Amr ElAhwany, MD, Department of Andrology, Cairo University, Cairo, Egypt, Tel.: +20 1144433325, E-mail: amralahwani@hotmail.com

ISSN: 2090-6048, June 2018, Vol. 8, No. 2

\section{INTRODUCTION}

Varicocele is defined by the presence of dilated tortuous veins of the pampiniform plexus. It is present in $\sim 15 \%$ of the general population, rising to $35 \%$ of men with primary infertility and $70 \%$ of those with secondary infertility. ${ }^{[1]}$. Dilated pampiniform veins are associated with declining semen parameters through various mechanisms, including left renal vein pressure increase ${ }^{[2]}$, incompetent spermatic veins valves, and the production of reactive oxygen species $^{[3,4]}$ Increased reactive oxygen species levels cause sperm DNA fragmentation and subsequently affect the fertilizing capability of spermatozoa ${ }^{[5]}$.

Surgical repair of varicocele results in semen improvement in $60 \%$ of cases, with a normal pregnancy rate of $30-40 \%{ }^{[6,7]}$. Various surgical techniques have been described for the treatment of varicocele, with the most prevalent gold standard technique currently being microsurgical subinguinal varicocelectomy, which has the least complications compared with other surgical techniques $^{[8]}$. However, it takes longer operating time and requires great surgical expertise ${ }^{[9]}$. Fisch et al. ${ }^{[10]}$ introduced a novel artery-sparing technique that requires shorter operating time and is easier to perform, as explored in this paper.

\section{Simplified subinguinal artery and lymphatic-sparing varicocelectomy technique}

This technique was first described by Fisch et al. ${ }^{[10]}$. The main idea of this technique is that the artery is carefully dissected from the underlying vascular bundle. Thereafter, the vascular bundle is ligated in the mass sparing the crossing artery above. In brief, a $2-3-\mathrm{cm}$ subinguinal incision is made, and the spermatic cord is delivered using a bubcock after blunt dissection through campers and scarpas fascia. The cord is then bluntly dissected from surrounding fat and fascia by the operator's finger and held over a penrose drain. Using a surgical loop $6 \times$, the cremasteric vein and external spermatic veins are first carefully dissected and ligated using 30 - silk sutures. Thereafter, the cremasteric and spermatic fascia are opened to expose the spermatic cord vessels. The cord is spread and tented over the surgeon's index finger, and vascular bundles are gently dissected from both overlying and underlying fascia and sheath, using a moist gauze. We applied a small modification in this step by using additional hydrodissection, with $3-\mathrm{ml}$ syringe filled with $0.9 \%$ saline, to gain the advantage of more separation of the lymphatic channels from the main vascular bundle.

After careful dissection of the vascular bundle, the 
artery was identified and located with the primary vascular bundles. Artery identification can be undertaken using various characteristics, including muscular structure, usually being located between crossing small veins, being brighter in color, sometimes pulsating if held in gentle tension, and blood filling from upward to downward. Experienced surgeons can clearly identify the spermatic artery when using magnification (Figs 1 and 2).

Once the artery is identified, it is dissected from surrounding veins using a microsurgical hemostat artery, then a 20 - silk is passed underneath the artery, to separate it from the primary vascular bundle, then below the vascular bundle in the opposite direction, separating the vascular bundle from the underlying sheath and lymphatic vessels. The silk thread then encircles only the primary vascular bundle and is tied firmly, locating the knot away from the artery. Thereafter, the remaining veins within the cord are ligated. At the end, the cord is brought back inside, and the scarpas fascia is closed by 30 - vicryl sutures followed by skin incision.

In our center, we started applying the 'Fisch' simple artery and lymphatic-sparing varicocelectomy technique from September 2015, based on the belief that this technique is simpler, saves time, and is less expensive than conventional varicocele technique, as explored in this paper.

\section{PATIENTS AND METHODS}

Ethical approval for our study was obtained from our local research ethical committee.

\section{Sampling}

We performed a retrospective review of 95 patients to compare the difference between the conventional microsurgical subinguinal procedure and 'Fisch' simple artery and lymphatic-sparing varicocelectomy technique. We selected 51 patients who underwent the former procedure between June 2015 and August 2015 (group 1), and 44 patients who underwent the Fisch et al..$^{[10]}$ technique from September 2015 to June2016 (group 2). All operations were done by a single expert surgeon in microsurgery, who performs more than 75 procedures per year.

All patients of both groups recruited in the study presented with bilateral palpable varicocele, were married with known infertility for more than 12 months, and had at least one abnormal parameter in three or more semen analyses.

Exclusion criteria included patients with recurrent varicocele, previous inguinal hernia repair, presence of chromosomal abnormality in their karyotyping, and positive Y-chromosome microdeletion in patients with oligozoospermia.

\section{Methods}

The two groups were compared regarding the operative time (in minutes), semen parameters improvements, pregnancy rate, and the appearance of complications (recurrence and hydrocele).

\section{Follow-up}

Follow-up after surgery was done for one year. The first follow-up was done one month postoperatively to evaluate the recurrence rate and hydrocele formation. The second follow-up was done 6 months after the surgery for semen analysis evaluation and possible occurrence of spontaneous pregnancy. The last follow-up was after 12 months.

\section{Statistical analysis}

Descriptive statistics were performed for semen health parameters at the 3-month, 6-month, 9-month and 12-month stages. A $\chi 2$-test was used to examine the association between techniques (Microsurgical and Fisch technique).

A paired t-test or Wilcoxon test was performed to assess the evolution of sperm quality between the preoperational level and the 1-month, 6-month, and 12-month review. Mann-Whitney test was used to compare the outcomes between both treatments at each moment and the operative time $(0,6$, and 12 months). Analysis of variance was performed on postoperative semen parameters (with logarithmic transformation when needed) to assess global difference between both treatments. All tests were two sided, and no adjustment for multiple comparisons was made. $P$ values less than 0.05 were considered statistically significant. Analyses were performed using SPSS software (SPSS Inc., Chicago, Illinois, USA).

\section{RESULTS}

The mean age of patients was $31.8 \pm 6$ and $31.5 \pm 7.5$ years in group 1 and group 2 , respectively. In both groups, there were no major intraoperative complications. At 6-month follow-up, the total recurrence rates were 4.5 and $2 \%$, respectively; despite group 1 recurrence being more than double that of group 2, this difference was not statistically significant $(P>0.05)$. Regarding hydrocele formation, group 1 manifested $2.3 \%$ hydrocele formation, compared with $5.8 \%$ for group 2 , again with no statistically significant difference $(P>0.05)$ (Table 1).

Semen analysis was done for every patient in both groups preoperatively and postoperatively. Both groups showed significant improvement in count, motility, and abnormal forms after operation.

Sperm motility and abnormal form improvements 
were higher in group 2, reaching significant difference: postoperative motility improvement for group 1 showed $41.6 \%$, compared with $47.2 \%$ for group 2 .

Group 2 showed a lower percentage of abnormal forms (83.7\%) compared with group 1 (95.5\%) (Table 2).

Concerning the pregnancy outcome, both groups showed similar pregnancy rates $(40 \%$ and $35.7 \%$ for group 1 and group 2 , respectively, $\mathrm{P}=0.3$, indicating no statistical significance).

The main goal of our study was to compare the operative time between the two groups. The average operating times of group 1 and group 2 were $94 \pm 6.9$ and $44.5 \pm 8.4 \mathrm{~min}$ $(\mathrm{P}=0.001)$, indicating a highly significant difference.

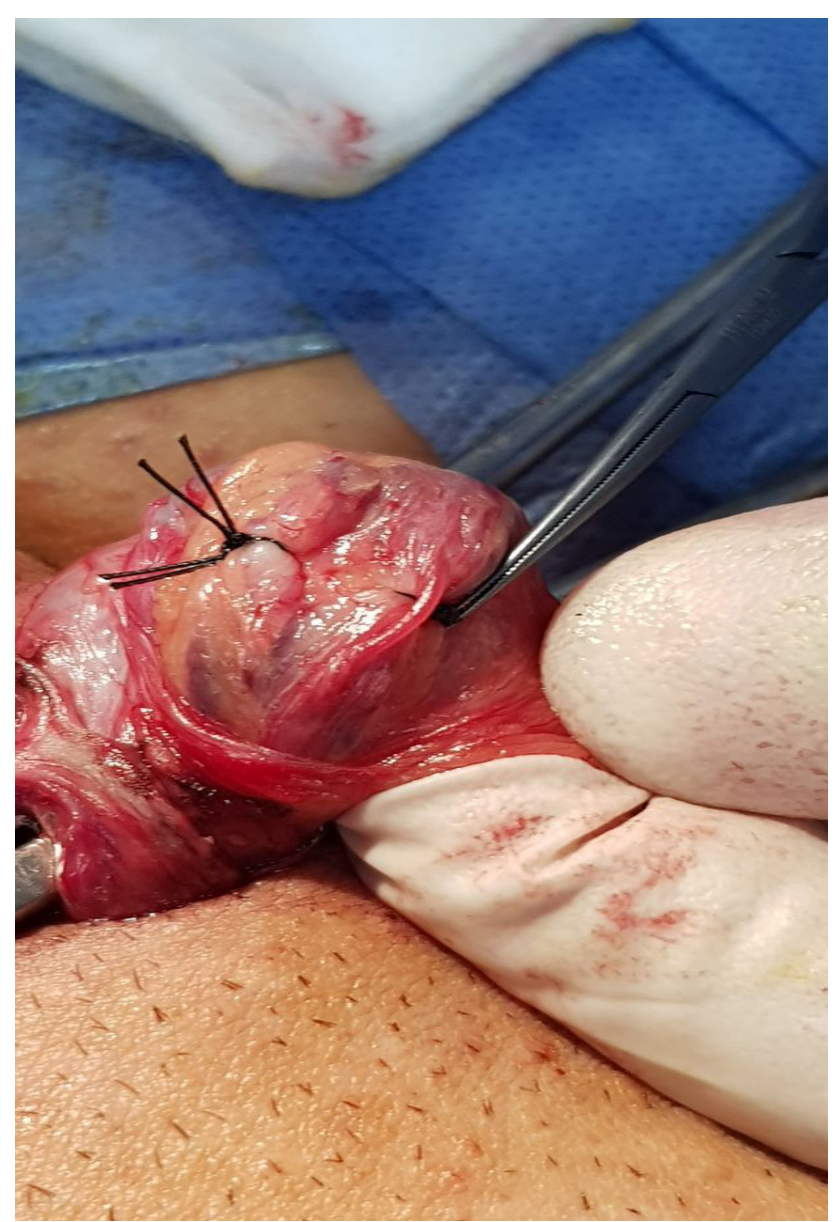

Fig. 1: The final result after vein ligation with artery sparing.

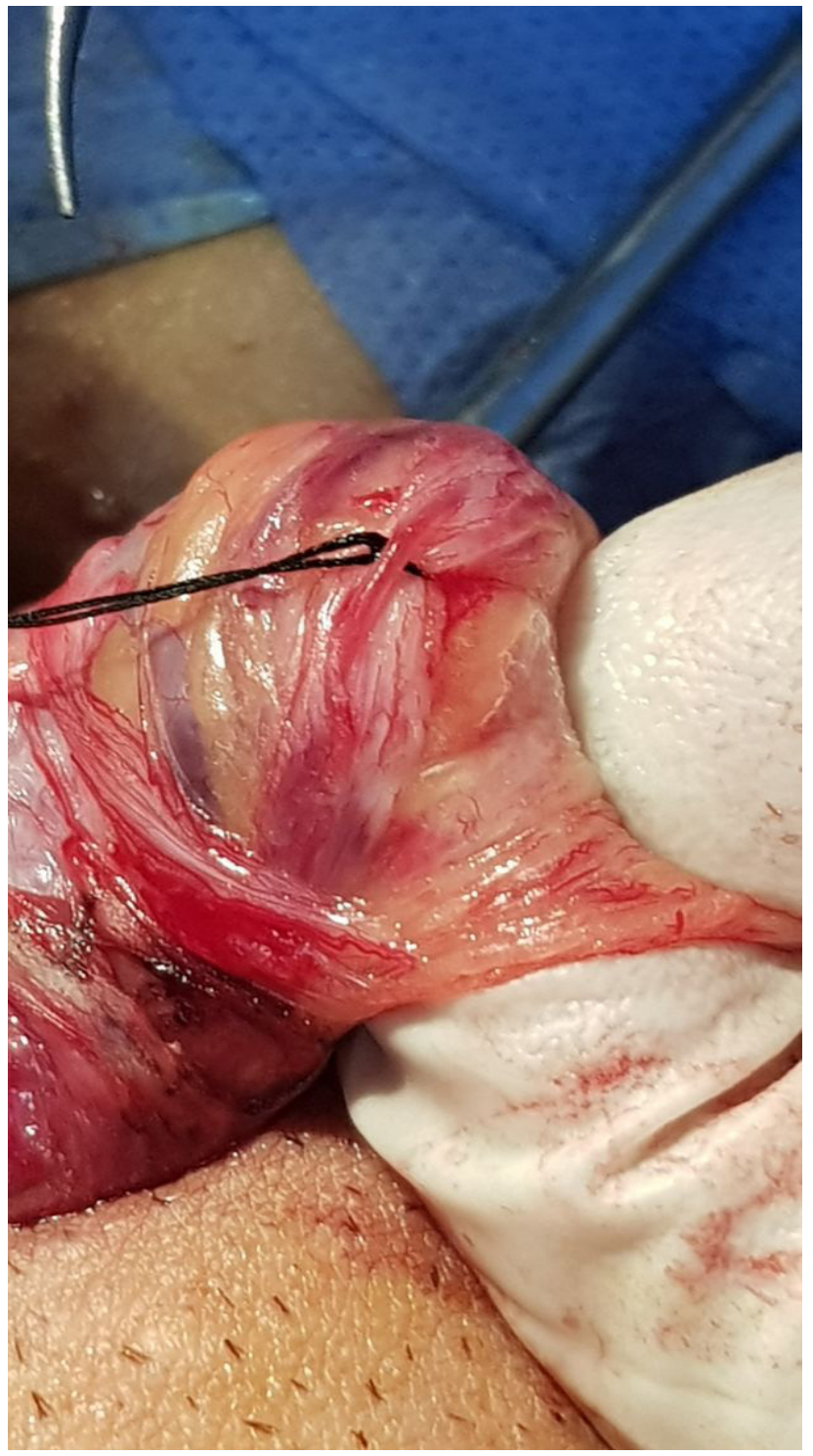

Fig. 2: The ligation of veins underneath the artery.

Table 1: Recurrence and hydrocele

$$
\text { Group } 1 \text { Group } 2 \text { Pvalue }
$$

\begin{tabular}{lccc}
\hline Number of patients & 51 & 44 & \\
Recurrence & 2 & 1 & $0.473(\mathrm{NS})$ \\
Hydrocele & 1 & 3 & $0.382(\mathrm{NS})$ \\
\hline
\end{tabular}

This table shows the complication rate regarding recurrence and hydrocele formation in both operated groups. 
Table 2: Preoperative and postoperative characteristics

\begin{tabular}{|c|c|c|c|}
\hline & Group 1 & Group 2 & P value \\
\hline Preoperative count & $16.8 \pm 14$ & $19.28 \pm 17.6$ & 0.7 (NS) \\
\hline Postoperative count & $36.4 \pm 21$ & $34.8 \pm 23.7$ & $0.5(\mathrm{NS})$ \\
\hline Preoperative motility & $26.9 \pm 12$ & $36.3 \pm 22$ & $0.06(\mathrm{NS})$ \\
\hline Postoperative motility & $41.6 \pm 15.4$ & $47 \pm 20$ & $0.04(\mathrm{~S})$ \\
\hline $\begin{array}{l}\text { Preoperative } \\
\text { abnormal forms }\end{array}$ & 94.9 & 95.5 & $0.5(\mathrm{NS})$ \\
\hline $\begin{array}{l}\text { Postoperative } \\
\text { abnormal forms }\end{array}$ & 93.2 & 83.7 & $0.004(\mathrm{~S})$ \\
\hline
\end{tabular}

This table compares the preoperative and postoperative semen characteristics regarding sperm count, motility, and abnormal forms. $\mathrm{S}$, significant.

\section{DISCUSSION}

A previous meta-analysis enrolling seven randomized controlled trials found no beneficial effect of varicocelectomy on male infertility in terms of pregnancy and birth rates between treated and non-treated groups ${ }^{[11]}$, but this was criticized owing to biased data, particularly as it included patients with normal semen and subclinical varicocel $^{[12]}$. Since then, other meta-analyses and studies excluding biased data have reached more authoritative findings. Baazzam and colleagues published a new metaanalysis about the efficacy of varicocelectomy on male infertility in which they concluded that varicocelectomy clearly improved semen parameters and pregnancy rates compared with the control group. This favorable outcome of varicocelectomy on male infertility was confirmed by subsequent meta-analyses ${ }^{[13-15]}$.

Different varicocelectomy techniques have been advocated worldwide, including surgical, radiological, and laparoscopic, each of which can be subdivided into multiple subtechniques that have been extensively explored and described in detail, with evaluation of their advantages and disadvantages in numerous studies and review articles ${ }^{[16,17]}$.

All recommendations favored microsurgical subinguinal varicocelectomy, which has the least recurrence and hydrocele formation rate and the best pregnancy outcome ${ }^{[18]}$. However, microsurgical varicocelectomy carries the disadvantage of being expensive, requiring expert surgeons, and long operation time duration and entailing extensive health care costs.

Having applied the simple varicocelectomy technique described by Fisch et al. ${ }^{[10]}$ since September 2015, we have experienced many advantages such as operative time saving, satisfying postoperative results and simplicity of surgical techniques, which can be easily taught to junior staff and thus improve general surgical outcomes.

In our current study, both groups showed a significant improvement in all semen parameters regarding count, motility, and abnormal forms. In group 2, there was a significant improvement regarding count and abnormal forms over the subinguinal microsurgical group.

Regarding the pregnancy rate, both groups showed almost the same outcome. These results are concomitant with most other studies done on varicocelectomy, which showed that one-third of the cases achieve spontaneous pregnancy ${ }^{[19]}$.

There was no statistically significant difference regarding the complication rates between the two groups. In group 1, two patients showed varicocele recurrence and hydrocele developed in only one case. In group 2, only one patient showed recurrence, whereas three patients developed hydrocele. Although these complication rates did not reach statistical significance, higher hydrocele occurrence in group 2 can be explained by the ligation of some lymphatics. However, the number of patients enrolled in our study is insufficient to support a definitive conclusion on this, and it would be an interesting avenue for future research. None of the patients who developed hydroceles were operated, as hydrocele formation was of minimal size.

Only one patient was re-operated for varicocelectomy recurrence. This patient was from the microsurgical group. All other patients who developed recurrences were not re-operated, as they showed mild degree of recurrent varicocele.

Regarding the operative time, our results indicate a dramatic decrease in operative time using Fisch technique (group 2) compared with subinguinal microsurgical varicocelectomy (group 1). The microsurgical group showed an average operating time of $94 \pm 6.9 \mathrm{~min}$, compared with $44.5 \pm 8.4 \mathrm{~min}$ for group $2(\mathrm{P}=0.001)$, indicating a highly significant difference. This carries the advantage of low operative time, thus exposing patients to less anesthesia time, reduced incidence of infection, and shorter hospitalization.

\section{CONCLUSION}

The treatment of varicocele by the modified arterysparing technique described by Fisch et al. ${ }^{[10]}$ shows equivalent results when compared with the classic subinguinal microsurgical approach, and it carries the advantages of much shorter operative time with almost the same postoperative complication rates. 


\section{ACKNOWLEDGEMENTS}

The author thanks Dr Hisham Elahwany for his help in paper editing.

\section{CONFLICTS OF INTEREST}

None declared.

\section{REFERENCES}

1. Goldstein M. Surgical management of male infertility. In: Wein A, Kavoussi LR, Novick AC, Partin AW, Peters CA, editors. Campbell-Walsh urology. Philadelphia, PA: Elsevier Saunders; 2012. 648-687.

2. Naughton CK, Nangia AK, Agarwal A. Pathophysiology of varicoceles in male infertility. Hum Reprod Update 2001; 7:473-481.

3. Kass EJ, Reitelman C. Adolescent varicocele. Urol Clin North Am 1995; 22:151-159.

4. Mostafa T, Anis TH, El-Nashar A, Imam H, Othman IA. Varicocelectomy reduces reactive oxygen species levels and increases antioxidant activity of seminal plasma from infertile men with varicocele. Int J Androl 2001; 24:261-265.

5. Shiraishi K, Takihara H, Matsuyama H. Elevated scrotal temperature, but not varicocele grade, reflects testicular oxidative stress-mediated apoptosis. World J Urol 2010; 28:359-364.

6. Agarwal A, Deepinder F, Cocuzza M, Agarwal R, Short RA, Sabanegh E. Efficacy of varicocelectomy in improving semen parameters: new metaanalytical approach. Urology 2007; 70:532-538.

7. Baazeem A, Belzile E, Ciampi A, Dohle G, Jarvi $\mathrm{K}$, Salonia A. Varicocele and male factor infertility treatment: a new meta-analysis and review of the role of varicocele repair. Eur Urol 2011; 60:796808 .

8. Schiff J, Kelly C, Goldstein M, Schlegel P, Schelgel P, Poppas D. Managing varicoceles in children: results with microsurgical varicocelectomy. BJU Int 2005; 95:399-402.
9. Zini A, Fischer A, Bellack D, Noss M, Kama $\mathrm{K}$, Chow V, Mak V. Technical modification of microsurgical varicocelectomy can reduce operating time. Urology 2006; 67:803-806.

10. Fisch H, Johnson CW, Bingham JB, Anastasiadis AG. A novel surgical approach to subinguinalvaricocelectomy: artery and lymphatic isolation technique. Urol Int 2004; 72:162-164.

11. Evers JL, Collins JA. Surgery or embolisation for varicocele in subfertile men. Cochrane Database Syst Rev 2004; 3:CD000479.

12. Dohle GR, Colpi GM, Hargreave TB, Papp GK, Jungwirth A, Weidner W, Infertility EAUWGoM. EAU guidelines on male infertility. Eur Urol 2005; 48:703-711.

13. Kroese ACJ, de Lange NM, Collins J, Evers JLH. Surgery or embolization for varicoceles in subfertile men. Cochrane Database Syst Rev 2012; 10:CD000479.

14. Nork JJ, Berger JH, Crain DS, Christman MS. Youth varicocele and varicocele treatment: a metaanalysis of semen outcomes. Fertil Steril 2014; 102:381-387.

15. Wang J, Xia S-J, Liu Z-H, Tao L, Ge J-F, Xu C-M. Inguinal and subinguinal micro-varicocelectomy, the optimal surgical management of varicocele: a meta-analysis. Asian J Androl 2015; 17:74-80.

16. Lomboy JR, Coward RM. The varicocele: clinical presentation, evaluation, and surgical management. Semin Intervent Radiol 2016; 33:163-169.

17. Owen RC, McCormick BJ, Figler BD, Coward RM. A review of varicocele repair for pain. Transl Androl Urol 2017; 6 (Suppl 1):S20-S29.

18. Diegidio P, Jhaveri JK, Ghannam S, Pinkhasov R, Shabsigh R, Fisch H. Review of current varicocelectomy techniques and their outcomes. BJU Int 2011; 108:1157-1172.

19. Jungwirth A, Giwercman A, Tournaye H, Diemer T, Kopa Z, Dohle G, et al. European Association of Urology Working Group on Male I. European Association of Urology guidelines on male infertility: the 2012 update. Eur Urol 2012; 62:324-332. 